\title{
La Crítica Social en las Fábulas de Marco Denevi
}

En el año 1955, la novela Rosaura a las diez obtuvo el primer premio en el concurso "América en la novela", organizado por la Editorial Kraft de Buenos Aires. Su autor, Marco Denevi, sorprendió a los lectores y a los críticos al confesar, en el prólogo de la obra, que los primeros pátrafos marcaban su iniciación como escritor: "Rosaura es mi primer libro; su primer párrafo, mi primer párrafo; la palabra con que comienza, mi estreno como (¿cómo decirlo?), como "ejercitador de las letras'."1

Hasta ese instante no había frecuentado otra actividad literaria que la lectura. El mismo dice: "Leía todo cuanto caía en mis manos: novelas, cuentos, poesía, filosofía; historia, y todo lo leía con la misma voracidad, con el mismo deleite, entreverando escuelas, géneros, autores". ${ }^{2}$

Nacido en 1922 en Sáenz Peña, suburbio de Buenos Aires, se graduó de bachiller en el Colegio Nacional de Buenos Aires. Más tarde estudió en la Facultad de Derecho y Ciencias Sociales de la Universidad de Buenos Aires, donde recibió el título de abogado. Al poco tiempo ob. tuvo el puesto de asesor letrado en la Caja Nacional de Ahorro Postal, en Buenos Aires, cargo que aún mantiene.

Hoy su reputación como escritor está firmemente establecida, por lo menos en la Argentina, con la obtención de varios premios literarios que han recompensado su labor como novelista, dramaturgo y cuentista. Rosaura a las diez ha sido reeditada en ocho oportunidades, tradu-

1 Citado por Donald A. Yates en su artículo bibliográfico, "Para una bibliografía de Marco Denevi", Revista lberoamericana, No 63 (enero-junio, 1967), 141. En dicha bibliografía no se mencionan cuatro "falsificaciones": "Biografía secreta de Nerón", "Paolo y Francesca", "El Emperador de la China" y "Otra versión de un Fénix demasiado frecuente", publicadas bajo el título de Cuenticulario en la revista Ficción, № 24-25 (marzo-junio, 1960), 398-400. Tampoco la fábula "Las abejas de bronce", aparecida en Sur, № 269 (marzoabril, 1961), 11-18.

2 Citado en la solapa de su obra Los expedientes (Buenos Aires: Editorial Talia, 1957). 
cida al alemán y al inglés, llevada al cine y adaptada por el autor para el teatro y la televisión.

Entre 1955 y 1960 publicó alrededor de una docena de cuentos y fábulas, varios de los cuales resultaron premiados. En 1957 su comedia en tres actos, Los expedientes, ganó el Premio Municipal; ella constituye una aguda crítica a la burocracia y al anacronismo de la administración pública argentina, centralizada en Buenos Aires. El éxito teatral le volvió a sonreir en 1960 , con El emperador de la China, obra en un acto que se mantuvo en el Teatro Botánico por largo tiempo.

El mismo año la revista Life en Español realizó un concurso de cuentos; entre más de tres mil recibidos, el enviado por Marco Denevi, Ceremonia secreta, obtuvo el primer premio. Un año más tarde fue adaptado para la televisión. Su segunda novela, Un pequeño café, apareció en 1966.

La obra de Denevi puede ser agrupada en tres sectores que lo presentan con tres modalidades distintas: $1^{\circ}$ ) el de creador de relatos de misterio (Rosaura y Ceremonia secreta); $2^{\circ}$ el de autor de cortas narraciones "antihistóricas", llamadas por él falsificaciones; $3^{\circ}$ ) el de crítico social.

Rosaura a las diez y Ceremonia secreta son dos relatos de corte po. licial y configuran un sector muy significativo de su narrativa. El juego con la tensión del lector, a través de una elaboración que mantiene una cierta intriga, se da en función de la presentación de situaciones conflictivas (soledad, abandono, vejez); así, el mantener suspenso (mantener una ambigüedad del relato) sirve para retratar determinados tipos humanos y sus contextos particulares.

Las falsificaciones, relatos cortos de gran riqueza imaginativa, narran episodios históricos o literarios, tal como ocurrieron de acuerdo a su modo original de ver la historia y se hallan impregnados de un vago arre filosófico e irónico. Se cierran con referencias históricas que marcan su irrealidad como una irrealidad específica, la de la ficción narrativa. ${ }^{3}$

Como crítico social, aspecto que nos interesa analizar en este trabajo, explora la deshumanización del hombre debido a la técnica moderna y a la actividad burocrática, en sus fábulas y en su obra dramática Los expedientes.

3 Durante los últimos años Denevi ha publicado, casi exclusivamente, relatos muy cortos, conocidos con el nombre de "microcuentos", que han alcanzado gran popularidad en Argentina. Otros argentinos que cultivan el microcuento son Jorge L. Borges, Adolfo Bioy Casares y Enirique Anderson Imbert. 
Definiremos la fábula como una ficción con que se encubre o disimula una verdad. En este tipo de relato, generalmente breve, de una acción alegórica, los personajes son por lo general animales, ocasionalmente seres humanos; sus conductas y comportamientos (narrados) encierran una instrucción, un principio general (de orden ético) que se desprende naturalmente del caso particular a que se refiere.4

La convención poética exige que al hacer hablar a los irracionales (y raras veces también a objetos inanimados), aunque hagan uso de modismos que imiten a los de los hombres, sólo se les atribuyan caracteres y costumbres que guarden alguna analogía con sus instintos y cualidades naturales, o con los que la tradición y la mitología les han atribuido. La fábula tiene sus orígenes en el impulso universal del hom. bre de expresar sus pensamientos por medio de imágenes concretas, de necesitar ver representadas, "exteriorizadas", vivencias interiores; por ello, mantiene estrecha relación con el uso de la metáfora en el lenguaje poético.

El estilo de la narración (discurso indirecto) y del diálogo (discurso directo) debe ser fácil, sencillo e ingenuo (el autor "cree" inocentemente lo que dice); ello tiende a lograr que, en un primer momento, no se establezca una mediación crítica entre lo narrado y el receptor, para que éste pueda aceptar las reglas peculiares de constitución de la fábula. Después veremos que ciertos elementos (comentarios, referencias específicas al lector, etc.) tratan de establecer esa mediación, de romper la ilusión de "realidad".

A pesar de su fin docente, este género literario es el más poético de todos los didácticos, por predominar en él la invención. Toda fábula contiene una moraleja, implicita o desarrollada explícitamente; al despojarse de ésta, se transforma en cuento.

Esto ocurre con las fábulas de Denevi, a quien le interesa más deleitar que adoctrinar éticamente: prevalece la materia narrativa. La sátira permea todas estas narraciones, que ponen de manifiesto los peligros que encierra para el hombre el constante avance tecnológico. Esta crítica está hecha con derroche de ingenio $y$ buen humor, mediante la

4 Véase al respecto: The Encyclopedia Britannica, v. IX (Chicago: Encyclopedia Britannica Inc., 1965); Enciclopedia Universal Ilustrada, t. XXIII (Barcelona: Hijos de J. Espasa, 1924); María Alicia Domínguez, Qué es la fábula (Buenos Aires: Editorial Columba, 1969); Herbert T. Archibald, Tha Fable as a Stylistic Test in Classical Greek Literature (Baltimore: J. H. Furst Co., 1912); Federico Ruano Cárdenas, Fábula, Apólogo, Parábola: concepto y diferencia (San Salvador: Ministerio de Defensa, 1954), y Mireya Camurati, "The Fable in Latin America" (Ph. D. Thesis, University of Pittsburgh, 1970). 
utilización de un lenguaje directo y económico, tendiente a la captación inmediata de lo que se cuestiona.

El tema que prevalece en las fábulas de Denevi, como veremos a continuación, es el de la pérdida de la libertad individual, de la dignidad personal y de la apreciación de lo bello en la naturaleza, todo esto producido a través de la gradual subordinación del hombre a los avan. ces de la sociedad altamente industrializada.

Las distintas fábulas de Marco Denevi se proponen y desarrollan una intención netamente crítica; su crítica es social y está dirigida a la denuncia de una sociedad enferma y deshumanizada por los adelantos de la tecnología y las caracteristicas que ésta imprime a las culturas industrializadas.

Podemos señalar, a modo de esquema, los principales tasgos que ellas registran (posteriormente, serán analizados en cada fábula) y que constituyen el centro de la crítica:

- subordinación (y posterior identificación) del individuo a la máquina: la deshumanización y la alienación;

- estereotipo y rigidez paulatinamente crecientes de los comportamientos individuales; de allí, la consecuente despersonalización, la pérdida de la identidad, la masificación;

- aceptación indscriminada de elementos y valores nuevos: el snobismo, la ingenuidad "a-reflexiva";

- el papel socialmente disminuido, casi irrelevante, de la capacidad creadora del hombre: una no valorización de la belleza y la pérdida de la obtención de placer;

- aumento de crisis y enfrentamientos personales y sociales: intensificación de las tensiones; un monto mayor de intolerancia $y^{\prime}$ agresividad capaz de llevar a la aniquilación y la destrucción;

- desaparición de la vida privada, de la intimidad; la invasión de lo personal;

- desvalorización y olvido de la naturaleza, cada vez más relegada, casi marginada de la actividad de los hombres.

La fábula Boroboboo ${ }^{5}$ muestra cómo una máquina computadora (simbólicamente la tecnología) es introducida a los animales del bosque. Esta incorporación de un elemento extraño, el aprendizaje de su mane-

5 Marco Denevi, "Boroboboo", en Novelistas contemporáneos bispanoamericanos (Boston: D. C. Heath, 1964); selección, prólogo y notas por Fernando Alegría. Todas las citas han sido tomadas de esta edición. Los números al final de las mismas indican las páginas de donde se han transcripto los textos. 
jo, produce un gran cambio en la fauna, feliz hasta ese momento. Desde este instante, todas las acciones y pensamientos serán dirigidos hacia la operación de la máquina, que termina subordinándolos.

Al comienzo, el relato presenta a los animales del bosque viviendo sin problemas, "felices, aunque en un estado de indescriptible atraso". (198) Sus progresos científicos eran nulos, y cuando se sentian enfermos la receta médica favorita, y única, era simple: se componía de "hierbas medicinales y una dieta de agua pura". (198)

Este estado de cosas, idílico y natural, tocó a su fin. La interrupción se produjo el mismo día en que llegó al bosque un simio, emisario de la lejana Ciudad de los Monos. Es necesario destacar que su descripción presenta un marcado contraste con la de los demás animales; éstos actuaban naturalmente; en cambio, el visitante "se movía con ademanes impecables, como si todo lo tuviera estudiado por anticipado". (199) Además, como notaron enseguida los animales del bosque, este visitante no olía a mono, sino a lavanda, y su voz poseía "un timbre agudo y metálico como la voz de un fonógrafo". (199) Su personalidad, fría, mecánica e imperturbable, se confirma al observar su modo de saludar:

- Enchanté - decía, mientras le estrechaba la mano a cada uno de los animales. -Enchantté. -Enchanté -seguia repitiendo el Mono-. Enchanté. $Y$ tendía la mano y miraba en los ojos al animal al que en ese momento saludaba. (199)

El Mono es caracterizado como un animal artificial, de juguete, al que se ha dado cuerda, con conductas y movimientos rígidos, automatizados.

Después de haber saludado a todos, el visitante subió a un árbol para hablarles a los animales del bosque y of recerles en venta una máquina, a precio muy reducido:

-Amigos míos - dijo, la Compañía Cibernética acaba de inventar una máquina que suma, resta, multiplica y divide; resuelve problemas de regla de tres simple y compuesta, $[\ldots]$ calcula intereses; opera con decimales y quebrados; eleva un número a cualquiera de sus potencias, extrae raíces, $[\ldots]$ reduce metros a yardas y $[\ldots]$; mide ángulos, triángulos $[\ldots]$; traza la bisectriz, la directriz, $[\ldots]$ conjuga los verbos regulares y los irregulares; enuncia las reglas ortográficas y sus excepciones, $[\ldots]$; dada una palabra, enumera sus sinónimos, antónimos, $[\ldots]$; re- 
dacta correspondencia comercial y privada y ciertos géneros menores de la literatura de ficción, como por ejemplo el apólogo; traduce a cualquier idioma romance, $[\ldots]$; modela, talla, esculpe $[\ldots]$; también canta, detecta el cáncer y la tuberculosis; domina la cinética, $[\ldots]$ no comete errores, no se fatiga, no se rebela, es amable, dócil y de aspecto agradable. Se llama EXTbbSHank00475Z115EGM, pero para abreviar tiene un sobrenombre: Boroboboo. (200)

Los animales quedaron fascinados al escuchar los atributos del nuevo invento, emitidos sin el menor titubeo por el Mono, quien les dio un dia para decidir sobre la compra de la máquina. Las deliberaciones que siguieron fueron hasta violentas; los más viejos se oponían a la compra pues sostenían que no les era de utilidad:

- ¿Para qué diablos la necesitamos? - chillaban. - Cómo para qué! —replicaban, enardecidos, los jóvenes. Una máquina que resuelve problemas de regla de tres simple y reduce metros a yardas y viceversa. (201)

Aunque ninguno de estos jóvenes sabia qué era un problema de regla de tres, o un metro y una yarda, lo cierto es que "aquellas palabras, misteriosas como conjuros, les producían erizamientos de placer". (201) Aquí Denevi critica en los jóvenes la infatuación, al parecer sin fin, que existe en el mundo moderno con la tecnología, aceptada como la cura para todos los males. En los paises industriales más avanzados, ésta ya se ha constituido en una nueva teología, que promete la salvación por medio de cosas materiales. Ähora los países llamados subdesartollados ven su "salvación" en esta nueva religión; como los jóvenes animales, parece sugerir el texto, escuchan embelesados a los nuevos sacerdotes, casi siempre extranjeros, que predican esta nueva fe desde sus templos técnicos.

De todos modos, podemos señalar que la crítica de Denevi adolece de cierta ingenuidad y de rigidez en cuanto a la aceptación $y / o$ incorpo. ración de elementos y valores nuevos, que puedan conmover o cuestionar los ya aceptados. La oposición tecnología/naturaleza (automatismo, frialdad, estereotipo opuestos a espontaneidad, placer, simpleza) en su formulación tajante encubre otros dos aspectos: el rechazo de lo nuevo y distinto por un lado; por otro, el problema que otorga sentido a esta polémica y que la ciencia debe resolver: la finalidad y la utilización concreta del avance tecnológico. 
Las actividades de Boroboboo están destinadas a producir, entre otras cosas, la castración del espíritu creador, pues podia modelar, tallar, es. culpir, pintar, dibujar, componer música y aun escribir. A pesar de todo esto, los jóvenes más alborotadores y con menos experiencia, se impusieron. La máquina fue comprada.

Al día siguiente regresó el Mono; el contrato, redactado en un idioma extranjero - dato sugestivo-, fue firmado. Inmediatamente después, el Mono eligió a los más inteligentes para enseñarles a manejar la máquina. Una vez elegidos, empezaron las primeras instrucciones sobre cibernética, rodeados del mayor secreto. Luego anunció que ese número era insuficiente y llamó a otros diez, y así sucesivamente hasta llegar a cien, los que "se pasaban todo el día en clase y la noche en vela estudiando la lección para el día siguiente. Al poco tiempo estaban ojerosos, macilentos y como en otro mundo". (202)

A pesar de ver los resultados de las lecciones en la actitud y aspecto físico de los cien estudiantes, los no elegidos se sentían desilusionados. Creían que esas lecciones producirian algo inefable. Su desencanto no duró mucho tiempo. En efecto, "el Mono explicó que la máquina era tan endemoniadamente compleja que exigía más servidores". (203) El número de los rechazados disminuyó hasta llegar a cero: ahora toda la comunidad estaba "sirviendo" a la máquina, aún ausente.

El empleo de palabras técnicas ("overflow", "bifurcar", "impriming", "bit" (203) facilita la ubicación del lector en el clima y contexto del relato.

A veces, la tensión originaba discusiones ininteligibles, polémicas que solian concluir en peleas; la paz se había terminado:

- No has entendido nada.

- Tú sí, tú sí has entendido. No sé cómo el Mono te permite asistir al curso...

- Oigan a este imbécil.

-Quítenme de encima a este idiota. (203)

Un día llegó el Mono con una novedad: la máquina había sido perfeccionada. Todo lo aprendido hasta ese momento debía ser olvidado. Había que empezar de nuevo. Los animales no pudieron hacer otra cosa que resignarse a aprender los nuevos métodos de manejo. Más tarde el instructor anunció que estaban a mitad del curso y, por lo tanto, ya podian elegir el sitio donde la máquina sería emplazada. Esta elección del lugar (el Mono elige el mejor pero siempre le parece pe- 
queño) significará por el progresivo talado de los árboles, la desaparición del bosque, de sus pájaros y animales, la evaporación del arroyo, el resquebrajamiento de la tierra: "Ya no hubo bosque, ni arroyo, ni nada, sino la llanura amarilla y desnuda como un páramo". (204)

Vemos cómo, en nombre de la técnica, la naturaleza ha sido desplazada, más aún, destruida. Se señala de este modo el peligro que significa para la naturaleza y para el hombre, la contaminación del ambiente, como su posible destructor; al mismo tiempo, queda marcada la relación existente entre este problema y la tecnología como su causa decisiva.

A todo esto, "los animales ya no trabajaban, ni jugaban, ni hacian nada, sino estudiar el manejo de la máquina. Vivían para la máquina. Vivian esperándola, soñándola”. (204) El proceso normal, la subordinación de la máquina al operador y sus requerimientos, se ha invertido. Ahora es ésta quien domina, la que hace de sujeto. Los animales han perdido todo concepto de autodeterminación, ya no son libres.

Los alumnos, soportando el sol implacable, habían llegado al último curso de cibernética, también dictado por el Mono. Su lenguaje era muy científico: "Código de bifurcación, subrutina abierta, lectura por carrete. Restaurar los ceros..." (204)

En esos momentos, la lechuza, que lo había estado observando con detenimiento, comprendió. Al instante se puso de pie y le preguntó:

- ¿Cómo te llamas?

Y el Mono, sin volverse, respondió con voz metálica:

-EXTbbSHank00475Z115EGM, alias Boroboboo. (205)

El Mono se había transformado en una máquina, en Boroboboo.

El relato hace suponer que el Mono estaba tan sometido e identificado con la máquina que, al final, insensiblemente, se convirtió en ella. Lo que se desprende de esta fábula es muy simple. Dicho brevemente: la tecnología esclavizará al hombre y destruirá a la naturaleza.

En cuanto a la técnica de este relato, observamos la ajustada caracterización de los pocos animales individualizados. Los rasgos que el texto destaca son los conocidos por todos, unos reales, otros simbólicos. Veamos algunos ejemplos.

Cuando el Mono saluda a los animales reunidos, su mirada los hace estremecer involuntariamente, incluidos "el León, el Tigre y hasta la mismísima Pantera Negra". (199) La pauta de la intensidad de la mirada del mico la da el hecho de que aun hace turbar a los tres animales 
más feroces del reino animal, incluida la Pantera negra, el carnívoro más agresivo.

Más tarde, al reunirse para considerar la compra de la máquina, el presidente de la asamblea no es otro que el León, lugar que le corresponde por ser el rey de la selva. En la asamblea la Serpiente, símbolo de la malicia, se decide - "insidiosamente"- por la adquisición de la máquina. Finalmente, la Lechuza, símbolo de la sabiduría, descubre que el Mono se había transformado en Boroboboo. A su vez, el Mono aparece como el animal más inteligente.

De acuerdo con el tono del relato, los párrafos son breves; las oraciones, cortas, se ligan por " $y$ "; escasean los adjetivos y faltan comparaciones y metáforas:

Después el sitio le pareció demasiado estrecho, y más árboles fueron derribados. $\mathrm{Y}$ siempre, a criterio del Mono, el claro destinado a la máquina era insuficiente, y había que ampliarlo. Y la tala de árboles continuó. (204)

En varias ocasiones, el narrador introduce observaciones o comentarios dirigidos a la actividad del lector para hacerlo partícipe del relato:

- ¿Se imaginan? (201)

Instantáneamente todos los animales (fíjense, todos, hasta la insignificante aguzanieves y el.... (202)

Este recurso también hace posible que el lector sea consciente de la ficción, que admita sus mecanismos y se constituya como destinatario del relato.

El final del cuento ilustra una de las técnicas que el autor usa con mayor efectividad: la del desenlace sorpresivo. En Denevi es difícil prever lo que harán los personajes. Aquí la metamorfosis que se produce en el Mono es absolutamente inesperada, y por ende, de mayor eficacia.

En la fábula "La cola del Perro"," los protagonistas son el Hombre y el Perro. Aquél ha decidido eliminar de su casa todo lo que sea gratuito, que para él es equivalente a inútil; entre otras cosas, le prohibe

"Marco Denevi, "La cola del Perro", en Ceremonia secreta y otros cuentos d.e Marco Denevi (New York: The Macmillan Co., 1965), con introducción, notas y vocabulario español-inglés por Donald A. Yates. Todas las citas han sido tomadas de la presente edición. Los números al final de las mismas indican las páginas de donde se han tomado los textos. 
al Perro que mueva la cola, ya que ello no tiene ninguna finalidad útil. Este tratamiento convierte al Perro en un animal tan eficiente y falto de afecto que, finalmente, se vuelve contra el Hombre.

En los primeros instantes, cuando el amo le ordenó no mover más la cola, el Perro sospechó que todo era una broma y le preguntó:

- ¿Por qué no quieres que la mueva?

- Porque he decidido eliminar de mi casa todo lo que sea gratuito.

- ¿Y qué es gratuito?

-Sinónimo de inútil. (15)

Seguidamente el Hombre le contó las medidas que ya habia tomado para suprimir en su casa todas las actividades gratuitas, sin ningún fin práctico. A tales efectos, había ordenado al Gato la caza de un ratón por día, al menos; al Caballo, que volviese a llevar el arado y abando. nara los trotes; a los Pájaros, que limpiaran de insectos el jardín, sin cantar. El Pavo Real, como no servía para nada, excepto para distraer al amo "con su gran cola petulante", había tenido un fin más trágico.

En este proceso destinado a lograr la absoluta organización de su entorno de acuerdo con los criterios de eficiencia y eficacia, el personaje pierde el gusto por la apreciación de la belleza visual y de la mú. sica, al matar al Pavo Real y prohibir los trinos de los pájaros, respectivamente. Esta pérdida de la posibilidad de gozar lo lleva a la deshumanización, a una absoluta rigidez y frialdad: la risa, la alegría, no significan nada más que ocio y frivolidad. Así, dice: "La risa vuelve estúpidos a los hombres lo mismo que a los perros. Es lo más gratuito que existe. Basta de risas. Basta de meneos de rabo". (16)

El sermón termina con la indicación precisa de la función del perro: el cumplimiento de sus deberes de guardián. Así el Hombre, al exigirle la supresión de todo acto placentero y demandar más dedicación en sus tareas, virtualmente convierte al Perro en una máquina, cuya única función es custodiar la casa del Amo.

Desde ese día la vida para el Perro no fue nada agradable. Tenía que hacer supremos esfuerzos para mantener la cola rígida cuando el Hombre le pasaba la mano por el lomo, para probarlo, o cuando Ia $\mathrm{Mu}-$ jer del Hombre le traía la comida. Como resultado de estas tensiones, una irritación constante lo dominaba y "se pasaba las horas disputando mentalmente con el Hombre. (18)

Una noche los esfuerzos del hombre empezaron a dar frutos; el perro había atacado en la huerta, en forma violenta, a un ladrón de 
manzanas. Este debió su vida a la oportuna llegada del amo, que separó al Perro. Después lo felicitó: “ßBravo, Perro, bravo!"

Este tipo de existencia frustrada había llevado al Perro a hablarse a sí mismo en voz alta. Los Pájaros en una ocasión lo oyeron y se rieron; ello provocó su ira y un pájaro pagó las consecuencias. El Hombre castigó al Perro con un palo pero éste no sintió el castigo; en verdad, ya no sentía nada, su sensibilidad había sido anulada. Extrañas alucinaciones pasaban por su cabeza; creía que estaba perdiendo la razón.

Entre los animales el Hombre descubrió un dia a una oveja muerta; al dia siguiente faltaba un cordero, algún lobo rondaba la granja. Esa noche esperó oculto entre los matorrales, con una escopeta, cerca del establo. Al poco tiempo distinguió la silueta de un Lobo, disparó y el animal cayó. El Hombre se aproximó y se detuvo, sorprendido: era el Perro. Decididamente el tratamiento del Amo le había llevado a la locura: se había creído un lobo.

Lo que Denevi plantea aqui es, creemos, el problema de la deshumanización, contradictorio, que parece siempre resolverse contra el hombre. En este caso el Perro fue convertido por el Hombre en un producto cuyo efecto era la eficiencia. Pero hemos visto cómo, al final, esta máquina eficiente se volvió contra el operador, el Hombre, al atacar los animales de su propiedad. El autor muestra así los peligros de la deshumanización. También debe notarse que, al igual que en "Boroboboo", el acento está puesto en la pérdida de la identidad: el perro se cree lobo, deja de ser él mismo, el mono se transforma en máquina. Ambos han abandonado sus comportamientos habituales y pierden la conciencia de su identidad personal.

En el transcurso de la ficción aparecen intercaladas apelaciones o referencias explicitas al lector, con la misma función que indicamos a propósito de la fábula ya analizada: "Los Pájaros, [...] levantaron la cabeza y se echaron a reír, sin ninguna mala intención, les aseguro". (19-20).

El lenguaje usado es claro, preciso, directo; se trata de un estilo eminentemente sustantivo, casi despojado de adjetivos, con oraciones cortas, sin imágenes. Esto crea, del mismo modo que en "Boroboboo", un ritmo ágil, con escasas detenciones en la descripción y notoria preferencia por la narración de los hechos.

La constatación de la verdadera identidad del Lobo por el Hombre confronta al lector de Denevi, una vez más, con un final sorpresivo. Por otro lado, un asunto trillado (la relación entre el hombre y el perro) adquiere visos de nuevo al recibir una conclusión inesperada. 
El relato "Fábula"7 presenta a los animales de una granja viviendo sin problemas, hasta que dos de ellos (el Gallo blanco y el Buey) sufren percances por no poder reconocer a sus "compañeros" de la granja. Ambos consideran que el hombre es el culpable de lo sucedido: "Aquí nadie sabe quién es quién..." (22), dice el Buey; "...la culpa es suya, Amo, $[\ldots]$ en su granja todo el mundo entra y sale y nunca se está seguro de con qué personas uno trata...," agrega el Gallo blanco. Conciben como solución que el Amo reorganice la granja, para lo cual se proporciona a cada habitante de la misma un documento de identidad. Esta nueva organización provoca una estructura burocrática, impersonal y rígida, que hace infeliz la vida de los animales y termina por anular su personalidad.

Ante el planteo de los animales, el Hombre, que tiene el hábito de escribir poemas (las referencias a la tarea de la escritura son casi una constante en Denevi), se olvida del que está componiendo en ese momento y consulta el problema con su esposa. Resolvieron que era necesaria la identificación de los animales por medio de un documento de identidad:

Los pesaron, los midieron, los fotografiaron [...] y finalmente les entregaron una tarjeta para que se la colgasen al cuello $[\ldots]$. En la tarjeta figuraban los datos personales de su dueño y la fotografía y al pie, enérgica y enrevesada, la firma del Amo. (25)

La tarjeta de identidad se convierte, poco a poco, en una parte del animal, en la garantía de su propia existencia (la Vaca afirma: - "El que no tenga tarjeta será como si no existiese".), en el único y absoluto medio de reconocerse a sí mismo. Llegará a ser, realmente, más importante que el animal en sí.

Es evidente aquí el paralelo que establece el relato entre este hecho y la situación en que se encuentra el hombre en el mundo moderno. El avance tecnológico, la burocracia, el consumo, han determinado que la existencia social del hombre se reduzca a un número, a una ficha, a un documento. El reconocimiento de sí mismo, la conciencia de su identidad personal, se logra sólo a través de una instancia exterior que lo afianza y determina (como veremos en el final de esta narración); el proceso de formación y toma de conciencia de la propia individualidad parece haberse invertido: se remite a la posibilidad de reconocerse sólo

7 Marco Denevi, "Fábula", en Ceremonia secreta y otros cuentos, edición citada. 
por la adjudicación de una serie de datos, por la atribución de una clasificación, de un rótulo.

Coincide con esta inversión de que hablamos, la paradoja de que sea el Asno (en la tradición literaria, un animal torpe y lento) quien se niegue a admitir 12 importancia de la tarjeta sobre su persona (quien: "ve" o comprende la realidad de los hechos).

Pasa el tiempo; el hombre se ha transformado. Sus actividades burocráticas (la consulta continua del libro de tapas rojas donde tiene registrados los datos de sus animales) han matado su apreciación de lo bello, cercenando su espíritu estético: ya no cultiva rosas ni escribe poemas. Su control aumenta cada vez más y ante dudas, vuelve a efectuar el trámite de identificación (peso, medidas, fotos, etc.).

Comienzan también, a raíz de ello, serios problemas para los animales: postergación y suspensión de comidas, peleas, discusiones. Posteriormente, el Hombre encontró insuficientes las informaciones que posé́a sobre los animales y decidió reestructurar el sistema sobre bases científicas, explorando la personalidad de ellos.

Aquí entramos en el problema de la invasión de la vida privada: la necesidad, en ciertos sistemas actuales, de información y de control de los actos del hombre, no se detiene ante las situaciones y hechos de índole privada. Esta necesidad se convierte en una tarea de espionaje, de invasión de lo estrictamente personal.

Con esta nueva operación, el proceso burocrático se expandió. El Hombre compró numerosos libros para volcar en ellos los nuevos datos que los interrogatorios aportaban. Cada animal llegó a ocupar un libro y "las tarjetas de identificación debieton ser ampliadas varias veces, a fin de dar cabida a los inifinitos datos que el Hombre consideraba como señas personales". (29)

Las esperas durante la hora de la comida se hicieron interminables debido a que el cotejo de los datos resultaba lentísimo. Tratando de hacer más eficiente la operación, el Hombre dividió a los animales por especie y les asignó un día determinado a la semana para comer, después de haber sido identificados.

La situación se torna desesperada: los animales se vuelven flacos y melancólicos; algunos se suicidan; sus peticiones no son atendidas.

La tarjeta, señal de su identidad, ya parte de sus propios cuerpos, los anula y destruye. La Vaca pensó, 'entonces, en una estratagema para convencer al patrón de la necesidad de modificar el sistema. Cambió tarjetas con el Gato y explicó su plan: 
- Me la colgaré al cuello, después me acercaré al Patrón, imitaré tus maullidos, le diré que, como la tarjeta dice que soy gato, me siento gato, $[\ldots]$ y no pienso dejarlo libre hasta que me prometa destruir todos los libros de tapa roja. (31)

Inesperadamente, un hecho increíble ocurrió: la Vaca se convirtió en Gato, y éste en Vaca. El relato termina consignando el cambio de sus identidades a través de sus predilecciones: la Vaca quiere un ratón, el Gato desea comer un bocado de hierba. La lección planeada para el hombre es olvidada.

El final de la narración muestra hasta qué punto habían llegado a estar supeditados a la tarjeta de identidad; el sistema los dominó: perdieron sus identidades en la medida en que sólo un hecho exterior y convencional les permitía saber quiénes eran.

El cierre de la ficción tiende a marcar los efectos de la tecnología y la estandardización en cuanto al problema de la identidad personal. El individuo subordina su personalidad (su accionar, sus ideas y sentimientos, su conciencia de sí) al papel o función que la sociedad le ha asignado, a pautas exteriores que resultan desintegratorias y destructivas.

Se repite en "Fábula" el recurso de la apelación al lector ("...la Vaca, fíjense bien, la Vaca...") como así también otros rasgos formales ya señalados: estilo simple, conciso y directo; recurrencia a la tradición popular en la caracterización de los animales; predilección por la coordinación y la construcción de oraciones breves; un ritmo narrativo ágil.

La división del relato en dos partes responde a una ordenación cro. nológica y acentúa el movimiento dramático de la acción narrada; la primera parte presenta el proceso de transformación de la granja, la segunda los efectos de la misma, varios años más tarde.

La fábula "La mariposa"8 toma como centro temático el progreso logrado por la progresista sociedad de las hormigas como resultado de sus avances técnicos: el descubrimiento del vegetal sintético les ha permitido autoabastecerse; ya no necesitan recurrir a la naturaleza para la obtención del alimento. Se forma un gran Hormiguero único y su gobernante ordena cerrar todas las salidas; esto les priva de libertad, las aisla del mundo real y todas se identifican en una labor alienada en la que pierden las nociones de individualidad $y$ nacionalidad.

8 Marco Denevi, "La mariposa", en Ceremonia secreta y otros cuentos, edi. ción citada. 
La historia comienza relatando cómo se producía el vegetal sintético, a cargo de hormigas obrexas: "mudas, ciegas, sordas, estériles, con el cerebro convenientemente lavado" (10), eran preparadas para segregar este producto, encerradas en células solitarias y oscuras. Estas hormigas simbolizan las fuerzas trabajadoras en la sociedad industrializada, condicionadas socialmente a la reiteración de una tarea mecánica que absorbe todos sus esfuerzos e impide el cuestionamiento, la toma de conciencia, el desarrollo de una verdadera actividad creadora.

Este adelanto técnico lleva a las hormigas a olvidarse de la naturaleza, del mundo exterior; se recluyen en los hormigueros, su mundo artificial.

El aumento de la población y la consiguiente multiplicación de los hormigueros originan la formación de un solo; este proceso de unificación no se logra sin luchas y ciertas oposiciones. El temor a la pérdida de los rasgos personales y de la libertad individual es confirmado desde las primeras medidas de la Gran Hormiga: borrar las fronteras, abolir las nacionalidades.

Subsistieron durante un tiempo (y nuevamente deben advertirse las referencias a la literatura como actividad social), relatos y leyendas sobre las vicisitudes de los más viejos de la comunidad en los momentos en que este proceso se fue produciendo. Finalmente, desaparecerán ("... dejaron de ocuparse de ellas...") (12): la nueva organización los elimina.

Es oportuno hacer notar que todas las fábulas de Denevi centran su interés explícito en los progresos de transformación de las sociedades animales (por analogía con los grupos humanos), en el registro de las situaciones de cambio, en sus connotaciones sociales y, sobre todo, psicológicas. Resultan partes integrantes de esa transformación, la actividad de la escritura y el lenguaje mismo. En este caso, la lengua de las hormigas pasará a ocuparse específicamente de sus nuevas actividades y se convertirá en un lenguaje parcializado en la nominación de los aspectos técnicos (situación que ya fue indicada en "Boroboboo"):

Las hormigas sólo hablaban de sistemas de lavado de cerebro, métodos de hibernación para las larvas nonatas, aplicaciones de la cibernética a la industrialización en gran escala del vegetal sintético y otros interesantes temas por el estilo. (12)

El extravío de una hormiga y el hallazgo casual de una salida abierta al exterior, le permiten tomar contacto con la naturaleza, conocer y apre- 
ciar la belleza y riqueza del mundo exterior. Aquí, el relato se detiene en señalar su asombro ("-iQué hermoso, qué hermoso es todo esto!") (13) y en contraponer su placer al recuerdo de sus hermanas, viviendo en las profundidades de la tierra, "alimentándose con una fría papilla envasada" (13). La hormiga regresa, convencida de que todas abandonarán el hormiguero; durante el retorno, "el olor a tierra húmeda y a encierro le provocaba náuseas; la cabeza le daba vueltas; le faltaba el aire..." (13). Se encuentra con un grupo de hormigas que discuten uno de sus últimos descubrimientos; al verla, éstas la toman por un monstruo:

Porque ahí, delante de sus ojos, había aparecido un monstruo, una criatura de pesadilla, un ser abominable. No era negro, como todas ellas, sino dorado, y de un cuerpo tan largo [...]. Antenas descomunales $[\ldots]$ cuatro membranas le brotaban del dorso, y estas membranas eran brillantes, tornasoladas, jaspeadas, amarillas [...]. Las hormigas no dudaron más. Se abalanzaron sobre el monstruo y lo mataron. (14)

Esta metamorfosis (la hormiga se ha convertido en mariposa) es el resultado de su recuperación de la libertad física e intelectual, de la posibildad de volver a su ambiente natural, del placer que le produce el contacto con la naturaleza. Esta imagen parafrasea, evidentemente, la situación del hombre en circunstancias semejantes. El cambio de la hormiga la hace aparecer ante los demás como un monstruo: la expansión de su sensibilidad y cuerpo, y la vigencia de su capacidad intelectual resultan desconocidas e intolerables para los demás. La mariposa simboliza al intelectual, al artista, en sintesis al individuo que ejercita su capacidad creadora en una cultura que la inhibe y que, por ello, es rechazado o incomprendido por los otros. El desdén y rechazo de este tipo de persona por la sociedad altamente automatizada, se identifica en el cuento con la muerte de la mariposa, criatura anormal para las hormigas.

A pesar de que el final es inesperado, quizás ilógico pues biológicamente la metamorfosis de la hormiga es imposible, el relato va dando ciertos sintomas y señales de dicha metamorfosis; estas indicaciones van entre paréntesis y están dirigidas al lector, a permitir la captación indirecta y paulatina de lo que se narra: " (¿Cómo, ella, tan minúscula, con sus pequeñas patas negras, podia saltar así?...)". Cuando regresa, le 
es difícil entrar en el hormiguero: "(¿por qué dificultosamente, si antes, al salir, la puerta se le había antojado monumental?)". (13)

El lenguaje, de acuerdo con el contenido, contiene términos puestos en uso por la industrialización: vegetal sintético, autoabastecimiento, cibernética, automatización industrial. El uso de oraciones cortas y abruptas con que empiezan y terminan algunas secuencias provee de dinamismo al relato:

Se encontró fuera del Gran Hormiguero.

Dio unos pasos como sonámbula.

Miró en derredor. (12)

Las comparaciones que hace la hormiga al salir del hormiguero son las que corresponden a sus limitados conocimientos y experiencias, en coherencia con el ámbito creado en la narración: "Vio la luna, igual que una Gran Hormiga redonda y blanca, y las estrellas que marchaban por el cielo como infinitas hormigas alucinadas." (13)

Las restantes características formales coinciden con las ya señaladas a propósito de las otras fábulas.

Finalmente, en la falsificación "Apocalipsis", ${ }^{9}$ Denevi nos da su versión de la extinción de la raza humana, provocada por las máquinas. El grado de automatización y de perfección de las mismas es tal que a los hombres "les bastaba apretar botones y las máquinas lo hacían todo por ellos." (9)

Ya los hombres "no necesitaban comer, ni dormir, ni leer, ni hablar, ni escribir, ni hacer el amor, ni siquiera pensar." (9) Gradualmente, todo desaparece, con la excepción de hombres y máquinas; estas últimas aumentan mientras los hombres son cada vez menos numerosos. No pueden moverse sin tropezar con alguna máquina, hasta que "finalmente, los hombres desaparecieron." (9)

El final es típico por su cierre brusco e impactante: "Como el último [de los hombres] se olvidó de desconectar las máquinas, desde entonces seguimos funcionando."

- Marco Denevi, "Apocalipsis", en Ceremonia secreta y otros cuentos, edición citada. 
Este relato, profético, resume lo que puede considerarse como la advertencia central de las fábulas de Denevi, el eje que las unifica y sintetiza los contenidos ya analizados en cada uno de los textos: la gradual destrucción del hombre por el avance tecnológico.

\section{José maría Carranza}

University of Indiana, $P a$. 